Article

\title{
Complicated Grief in the Aftermath of Homicide: Spiritual Crisis and Distress in an African American Sample
}

\author{
Robert A. Neimeyer * and Laurie A. Burke \\ Department of Psychology, University of Memphis, Memphis, TN, 38152, USA; \\ E-Mail: laburke@memphis.edu \\ * Author to whom correspondence should be addressed; E-Mail: neimeyer@mac.com; \\ Tel.: +1-(901) 494-1806; Fax: +1-(901) 678-2579.
}

Received: 10 May 2011; in revised form: 23 May 2011 / Accepted: 3 June 2011 /

Published: 14 June 2011

\begin{abstract}
Both grieving the loss of a loved one and using spirituality or religion as an aid in doing so are common behaviors in the wake of death. This longitudinal examination of 46 African American homicide survivors follows up on our earlier study that established the relation between positive and negative religious coping on the one hand and complicated grief (CG) on the other. In the current report, we broadened this focus to determine the relation between religious coping and other bereavement outcomes, including posttraumatic stress disorder (PTSD) and depression, to establish whether religious coping more strongly predicted bereavement distress or vice versa. We also sought to determine if the predictive power of CG in terms of religious coping over time exceeded that of PTSD and depression. Our results suggested a link between negative religious coping (NRC) and all forms of bereavement distress, whereas no such link was found between positive religious coping (PRC) and bereavement outcomes in our final analyses. Significantly, only CG prospectively predicted high levels of spiritual struggle six months later. Clinical implications regarding spiritually sensitive interventions are noted.
\end{abstract}

Keywords: religious coping; religious struggle; spiritual crisis; bereavement; complicated grief; PTSD; depression; African American; homicide

Abbreviations: CG: complicated grief; PTSD: posttraumatic stress disorder; MDD: major depressive disorder; PRC: positive religious coping; NRC: negative religious coping; CSG: complicated spiritual grief: CGs: complicated grievers; NCGs: non-complicated grievers; 
Time 1: T1; VTV: Victims to Victory; ICG-R: Inventory of Complicated Grief-Revised; PCL-C: PTSD Checklist-Civilian Version; BDI-II: Beck Depression Inventory II; TSL: time since loss.

\section{Introduction/Background}

Although grief is the common response to the loss of a loved one, it is also a psychological process that aids the griever in adapting to the loss. On one level, grief, like loss, is permanent. Both painful and pleasant memories of the deceased will resurface again and again across time. On another level, the frequency and intensity of distressing emotions usually diminish with the passing of time. At least when losses are normative, as in the death of a loved one by natural causes, approximately $45-50 \%$ of bereaved individuals respond resiliently to loss, with signs of significant mourning subsiding rather quickly [1]. Other bereaved individuals continue to respond to acute grief symptoms for a year or two after the loss [2]. Research also indicates that a subset of grievers struggles significantly and for a prolonged period of time from an extended, incapacitating, and sometimes life-threatening grief response known as complicated grief (CG; [3,4]; also termed prolonged grief disorder, PGD; [5,6]). Studies show that some losses are more difficult than others to endure, especially when death occurs as a result of suicide, homicide, or fatal accident [7], when indicators of distress may persist at high levels for years with little attenuation over time [8]. Research also indicates that African Americans experience homicide much more frequently than do Caucasians [9], and that loss of loved ones to violent death often prompts struggles for meaning that have been linked with problematic adaptation [10].

Reviews of studies on spirituality and religion (Although not synonymous, spirituality and religion are used interchangeably throughout this study for sake of simplicity in reporting research.) in bereavement indicate that spirituality plays a significant part in the accommodation of loss for many grievers [11,12]. However, although research shows that spirituality is highly important to African Americans more generally [13], it appears to be critically important to them after the death of a loved one, and especially when confronted with tragic loss [14]. African Americans often find that their spiritual beliefs and religious practices help to modulate the effects of loss [15] by offering, for example, a hopeful sense of peace in terms of reunion with their loved one in the afterlife. However, when grieving goes awry — when mourners experience acute separation distress, confusion about their role in life, or an inability to accept the loss - as is often the case for those who suffer from CG (e.g. $[16,17]$ ), one's sense of relationship to God and/or religious community easily can be undermined.

Researchers have recently explored spiritual struggle [18] and spiritual crisis [19] in distressed individuals. However, most research to date has examined the connection between bereavement outcome and religious coping in cross-sectional studies (see [12], for full review), often assuming that the latter predicts the former. In contrast, recent research suggests that the opposite relation could be at least as significant: bereavement distress may forecast later spiritual struggle [20]. 


\subsection{Bereavement Outcomes}

Studies by Bonnano and Mancini [2] and others have shown that major depressive disorder (MDD) represents a common form of bereavement distress, and accordingly measures of depression have predominated in studies of adaptation in bereaved samples. However, other forms of distress, such as posttraumatic stress disorder (PTSD; [2]) and CG [3] have been shown to have incremental validity in terms of predicting bereavement outcome [16,21,22]. Thus, a more comprehensive assessment of adaptation following loss should include depressive, post-traumatic, and complicated grief symptomatology.

Complicated grief is a condition represented by prolonged grieving, reflected in terms of profound separation distress, psychologically disturbing and intrusive thoughts of the deceased, a sense of emptiness and meaninglessness, trouble accepting the reality of the loss, and difficulty in making a life without the deceased loved one [23]. At the extreme end of a continuum that also encompasses more normative responses to loss [24], CG has a prevalence rate of approximately $10 \%$ in the general bereaved population [22]. However, recent studies, using a variety of samples, show higher prevalence rates in vulnerable groups. These include samples of African American cancer caregivers, with CG rates of $22 \%$ [25], bereaved parents, with rates of 30\% [26], victims of terrorism, with rates of $44 \%$ [27] and African American homicide survivors, with rates of 55\% [28]. Although more research is needed, recent studies also have established violent death as a potential risk factor for CG [7,26,29] and have associated CG with a spiritual struggle in terms of meaning making regarding the loss [30]. With the homicide rate for African Americans at ten times that of Caucasians [31], these findings are concerning, and call for more research on how spiritually inclined individuals in that community adjust to violent death losses.

\subsection{Spiritual Coping}

Human beings vary in their response to loss $[16,32]$ just as they vary in how they cope with stress in general [33]. As an important subset of coping responses, religious coping has been conceptualized in a variety of ways. Pargament, Smith, Koenig, and Perez [34] conceptualized positive religious coping (PRC) as: "an expression of a sense of spirituality, a secure relationship with God, a belief that there is meaning to be found in life, and a sense of spiritual connectedness with others" (p. 712). They conceptualized negative religious coping (NRC), on the other hand, as "spiritual discontent, punishing God reappraisals, interpersonal religious discontent, demonic reappraisals (attributing the event to the work of the devil), and reappraisals of God's power" (p. 710). Interestingly, Hills, Paice, Cameron, and Shott [35] and Pargament, Koenig, Tarakeshwar and Hahn [36] found that not only is it possible but also commonplace for individuals to use both PRC and NRC at the same time.

Researchers have theorized that religious coping functions as a means of finding meaning [37], gaining control of a stressful situation, gaining God's comfort and closeness, gaining intimacy with others, and in achieving a life transformation [38]. Similarly, Büssing and Koenig [39] stressed the importance of spiritual coping for sufferers of chronic illness. They outlined four core dimensions of spiritual needs: Connection, Peace, Meaning/Purpose, and Transcendence, which might be influential 
in the overall medical progress and recovery for seriously ill patients, extending the concept of using spirituality as a tool for coping beyond the simple delineation of PRC and NRC.

For individuals facing crisis [19], and particularly when facing the death of a loved one, religion and spirituality are often relied upon as a frontline means of coping. This is particularly true of African Americans [15], who endorse spirituality at rates significantly higher than do Caucasians [13]. Reviews of the role of faith in bereavement have concluded that spirituality provides a constructive foundation for adaptation to loss [11,12]. Still, very few studies have examined religious coping specifically as it relates to grief, and, most that have, have done so in terms of the benefits of spirituality in the wake of loss $[11,12]$. Thus, understanding how the condition of being bereaved might subsequently affect one's spirituality is grossly under-explored.

Although there are numerous ways to use one's faith as a coping strategy, one obvious resource is in gravitating toward one's spiritual community during difficult times. In some studies, church attendance has been associated with better bereavement outcomes [40-42], and yet results from other studies examining the benefits of spiritual social support imply that grievers do not always feel ministered to by their spiritual community. Richardson and Balaswamy [43] found for example that widowers who regularly attended church services had less positive and more negative affect than those who attended less regularly. One plausible explanation might be suggested by reports from mourners who express feeling a sense of abandonment or isolation from others while they are grieving, or in some cases enduring negative interactions that unnecessarily complicate an already difficult grieving experience [44].

Just how spirituality relates to bereavement outcome requires more attention. For example, spiritual coping was negatively associated with grief following the loss of a child who died in the pediatric intensive care unit [45], such that those who used more PRC suffered less grief. Conversely, in Tarakeshwar, Hansen, Kochman, and Sikkema's [46] study of 252 HIV-positive mourners, they found a significant main effect for PRC - individuals who used more PRC reported higher levels of grief. Anderson, Marwit, Vandenberg, and Chibnall [47] uncovered similar, albeit more complex, results. In their study of 57 mothers who lost a child to homicide, motor vehicle accident, or other fatality, they found that neither NRC nor PRC was statistically significant in relation to grief when assessed alone. Yet, when post-loss duration of the mothers was controlled, an interaction effect was discovered between PRC and task-oriented coping (taking charge of the stressful event with a specific goal in mind), indicating that mothers who used PRC in tandem with task-oriented coping subsequently fared better in terms of their grief. In their cross-sectional study of 150 homicidally bereaved individuals (most of whom were African American females), Thompson and Vardaman [48] found that grievers used both PRC and NRC (assessed using the RCA; [49]) in their effort to adjust. In terms of the relation between religious coping and distress (as measured by levels of anxiety, depression, posttraumatic stress, somatization, and hostility), they found, that, generally speaking, higher levels of PRC predicted lower levels of distress. In contrast, NRC, (i.e., feeling angry or distant toward God or members of the church and pleading with God for a miracle), predicted increased levels of distress. Overall, in a variety of studies, NRC consistently has been linked with deleterious outcomes [50]. 


\subsection{Spiritual Struggle}

Faith can be both a source of strength and a source of conflict [34]. Findings from Pargament et al.'s [36] longitudinal study spanning two years suggested that even when all other variables were controlled, spiritual crisis was the strongest predictor of forthcoming death in medically ill elderly patients, which signals the severity of this type of response to stress or loss. Despite the fact that distressed individuals typically use more PRC than NRC [35,36], spirituality is not always reassuring in terms of adaptation to loss. In fact, loss can precipitate spiritual struggle [51] and is often expressed in terms of anger toward God or in an inability to accommodate the notion that a good God would allow a loved one to die [52], especially when the death is grotesque or horrific. Unfortunately, little is known about how people fare when their usual methods of spiritual coping fail [11], or specifically when faced with grieving a violent death.

Individuals who have suffered atrocities, such as homicide, might be more prone to feeling or expressing extreme anger toward God [53]. Edmondson et al. [18] asserted that distressed individuals experience religious struggle when they sense that they are at the mercy of a controlling yet indifferent God who lacks compassion, are being unfairly disciplined by Him or, perhaps worse yet, completely forsaken. Thus, because faith is an important part of grief for many survivors, and because it may be particularly challenged following violent death, it is crucial to develop a better understanding of spiritual struggle and spiritual crisis in order to assist these underserved populations.

\subsection{Spiritual Crisis Following Loss}

A pilot study conducted between researchers [51] and a Pittsburgh church's bereavement response team, in an effort to develop a church-based grief intervention, illustrated the role of grief and bereavement in affecting one's spiritual well-being. The multi-disciplinary team examined the grief responses of 31African American church members who, in most cases, were bereaved by natural rather than violent causes. Parishioner's self-reports revealed that although the effects of loss on the griever's faith ranged from "faith stronger than ever" to "faith seriously shaken," $19 \%$ of the participants reported experiencing some degree of negative shift in their faith as a result of the loss. From this, Shear and her colleagues determined that spirituality plays a crucial role following loss for spiritually inclined individuals, in that they not only appear to experience the loss on a relational level in terms of their loved one but also on a spiritual plane where deaths are viewed as something orchestrated by God. Shear and her colleagues argued that experiencing grief religiously is similar to experiencing grief psychologically, where reactions to loss are viewed on a continuum of highly resilient to severely complicated responses, with the most problematic spiritual response being termed complicated spiritual grief (CSG; [51]). CSG has been conceptualized as a spiritual crisis in the mourner's relationship with God, such that he or she struggles to reestablish spiritual equilibrium following loss, often accompanied by a sense of discordance, conflict, and distance from God, and at times with members of one's spiritual community [51].

Although some individuals benefit from spiritual struggles stemming from existential crises, others indubitably do not. When core constructs or understandings of the universe are challenged, such as when adolescents are bereaved of their siblings [52], the survivor's faith can be severely shaken. From 
that place of spiritual crisis, one young teen responded with contempt: "I don't really care now about sinning.... It doesn't matter to me as much... since (my brother's death). I guess it is my way of getting back at God"' (p. 542). As Hill and Pargament [19] stated, for some distressed individuals, suffering a spiritual crisis constitutes the death of their faith, per se.

Burke and her colleagues [20] demonstrated, through a series of multivariate analyses exploring bereavement distress and spiritual crisis, that CSG is a serious, yet understudied, form of bereavement distress. Their longitudinal study of 46 African American homicidally bereaved individuals revealed that not only did survivors demonstrate greater use of religious coping more generally than did individuals in other samples, such as distressed college students, Oklahoma City bombing survivors, medical inpatients [34], medically ill elderly [36], and dying patients [35], but also that their level of spiritual struggle (as assessed by NRC scores on the Brief RCOPE) [34] was nearly twice as high in comparison. Additionally, they found that CG was associated with NRC at both Time 1 (T1; initial interview) and Time 2 (T2, 6-months later) and that PRC was uncorrelated with CG at either time point. Moreover, CG at T1 predicted NRC at T2, but the opposite did not hold true (NRC at T1 did not predict CG at T2). When examined on an item-by-item level, they found that T1 CG proved significant in predicting four out of seven items on the T2 NRC subscale-specifically in terms of the griever wondering what he/she did to receive God's punishment, questioning God's love, feeling abandoned by the church community, and questioning the power of God.

When Burke and her co-authors [20] bifurcated their sample into survivors who screened positive for CG (complicated grievers; CGs) and those who did not (non-complicated grievers; NCGs), they found that CGs experienced higher levels of NRC than did non-CGs, but that there was no difference between the two groups in terms of PRC. When testing to see if specific CG symptoms at T1 might prospectively predict subsequent religious coping items, they found elevated mean scores on three items from the Inventory of Complicated Grief-Revised (ICG-R; [23]) \#1 feeling devastated/overwhelmed by the death, \#5 longing/yearning for the deceased, and \#7 feeling angry about the death - in comparison to other items on the scale. Yet, only \#5, longing/yearning for the deceased, the theoretically central feature for diagnosis of CG [22], was statistically significant in prospectively predicting spiritual crisis, in terms of the griever's questioning what he/she did to receive God's punishment, questioning God's love, and feeling abandoned by the church community. Finally, in their sample, overall, levels of NRC decreased over time, but the rate of decrease in NRC scores for the CG group was substantially less than the rate of decrease for the non-CG group. For those individuals whose NRC scores increased, the CG group reflected a greater increase - a rate that was $56 \%$ higher than the non-CG group.

Thus, Burke et al. [20] established a strong link between CG and subsequent spiritual crisis. In fact, their results substantiated that, in comparison to non-symptomatic grievers, individuals in their sample with high levels of both CG and NRC might need more than simply compassion and the passage of time in order to successfully adapt to traumatizing loss. Rather, specialized psychotherapy interventions targeting CSG symptoms are likely necessary for some grievers, especially for spiritually inclined survivors of violent death. 


\subsection{Aims of this Study}

Homicide loss is a particularly devastating type of stress to endure [7], one that disproportionately affects African American communities [9], and can manifest itself through several deleterious forms of bereavement outcome, including CG, PTSD, and depression. Studies show that faith is important during times of stress [19] and during times of loss [11,12] and that distressed individuals frequently engage in both PRC and NRC, often simultaneously [35,36,48]. Therefore, because we know that PRC and NRC were differentially related to CG in our previous study [20], we sought to discover if the same was true for PTSD and depression in our sample of homicidally bereaved individuals. Thus, we hypothesized that, as with CG, PTSD and depression would be unrelated to PRC and directly correlated with NRC.

Previous studies examining CG in samples of spiritually inclined grievers have suggested that profound grief might trigger a spiritual crisis in some individuals [51]. In our previous study of African American homicide survivors, we demonstrated the predictive nature of $\mathrm{CG}$ as a prospective risk factor for spiritual crisis in violently bereaved individuals [20]. Because we found that CG not only predicted NRC on a global level but also did so on an item-by-item level, we were particularly interested in whether $\mathrm{CG}$ would uniquely predict an attachment struggle with God, beyond the variance explained by other forms of bereavement distress. Given that CG represents an intense feeling of separation distress following the loss of a primary attachment figure, and has been closely linked to spiritual discord and distress in the bereaved person's relationship to God and his/her spiritual community [20,51], we hypothesized that CG at T1 would better predict NRC at T2 than would PTSD and depression.

\section{Method}

\subsection{Participants}

Participants were 46 African American homicidally bereaved adults recruited into the study through Victims to Victory (VTV), a faith-based organization that collaborates with local law enforcement agencies to offer crisis counseling, victims' advocacy, and other services to survivors of homicide victims in a large city in the mid-South. Although VTV conducts a homicide support group, it is not specifically a mental health agency, and offers its services regardless of the survivor's faith tradition or lack of one. Several recruitment strategies were employed, including phone contacts, mailings, word of mouth, and distribution of brochures at VTV's bi-weekly support group meetings. We also were given access to their client contact database, which enabled us to make contact via phone and mailings with survivors who had had contact with VTV in the previous three years. Finally, some individuals joined as a result of hearing about our study from previous participants, all of whom received study brochures at the end of the first session. The exact number of people who heard about our study is unclear because of the multiple methods used to promote the project, including word-of-mouth. Of the 137 people with whom our staff had phone conversations, 15 declined participation. Reasons for not joining included: not ready to talk about the loss $(n=5)$, too busy $(n=5)$, not interested in research $(n=1)$, too sick to participate $(n=1)$, too close to the holidays $(n=1)$, or did not speak English $(n=1)$. One person did not give a reason. Many others expressed interest but did not schedule assessment 
appointments or repeatedly missed or canceled appointments. Participant background information is reported in Table 1.

Table 1. Descriptive Statistics for Background Variables, Bereavement Outcome, and Religious Coping for African American Adults Bereaved by Homicide ( $\mathrm{N}=46)$.

\begin{tabular}{|c|c|c|c|c|c|}
\hline$\underline{\text { Measures }}$ & $\underline{\text { Range }}$ & $\underline{M(S D)}$ & $\%(\mathrm{n})$ & $\begin{array}{r}\text { Time } 1 \\
\text { M (SD) } \\
\end{array}$ & $\begin{array}{r}\text { Time } 2 \\
\text { M (SD) } \\
\end{array}$ \\
\hline Positive religious coping & & & & $17.8(3.9)$ & $17.2(5.1)$ \\
\hline Negative religious coping & & & & $5.3(5.0)$ & $4.6(4.8)$ \\
\hline Complicated grief & & & & $79.1(23.2)$ & $69.9(24.1)$ \\
\hline PTSD & & & & $35.5(14.9)$ & $33.7(14.6)$ \\
\hline Depression & & & & $14.6(10.7)$ & $11.9(11.3)$ \\
\hline \multicolumn{6}{|l|}{ Demographic Variables } \\
\hline Months since loss & $1.1-58.3$ & & & $\begin{array}{c}1.69 \mathrm{yrs} \\
(1.20 \mathrm{yrs})\end{array}$ & $\begin{array}{c}2.19 \mathrm{yrs} \\
(1.70 \mathrm{yrs})\end{array}$ \\
\hline Age & 19-71 yrs & $50.23(11.36)$ & & & \\
\hline \multicolumn{6}{|l|}{ Race } \\
\hline African American & & & $100(46)$ & & \\
\hline \multicolumn{6}{|l|}{ Sex } \\
\hline Female & & & $89.1(41)$ & & \\
\hline Male & & & $10.9(5)$ & & \\
\hline \multicolumn{6}{|l|}{ Kinship } \\
\hline Spouses & & & $10.9(5)$ & & \\
\hline Mothers & & & $58.7(27)$ & & \\
\hline Fathers & & & $2.2(1)$ & & \\
\hline Step-fathers & & & $4.3(2)$ & & \\
\hline Sisters & & & $8.7(4)$ & & \\
\hline Extended family & & & $15.2(7)$ & & \\
\hline \multicolumn{6}{|l|}{ Marital Status } \\
\hline Married & & & $26.1(12)$ & & \\
\hline Single & & & $26.1(12)$ & & \\
\hline Separated/Divorced & & & $30.4(14)$ & & \\
\hline Widowed & & & $17.4(8)$ & & \\
\hline \multicolumn{6}{|l|}{ Education } \\
\hline$<$ High school & & & $10.8(5)$ & & \\
\hline High school/GED & & & $26.1(12)$ & & \\
\hline Some college & & & $37(17)$ & & \\
\hline College & & & $19.6(9)$ & & \\
\hline$>$ College & & & $6.5(3)$ & & \\
\hline \multicolumn{6}{|l|}{ Income } \\
\hline$<\$ 20,000$ & & & $37.1(17)$ & & \\
\hline$\$ 20,000-50,000$ & & & $45.6(21)$ & & \\
\hline$>\$ 50,000$ & & & $17.3(8)$ & & \\
\hline
\end{tabular}




\subsection{Procedure}

Following the university's Institutional Review Board's approval, participants met with a trained graduate student for the first assessment (T1), which consisted of signing an informed consent, participating in a brief audio-taped, semi-structured, open-ended interview and completing a number of paper and pencil measures (see Measures section). The interviews were incorporated simply to build rapport, through the use of two questions: (1) "I did not have the pleasure of knowing [loved one], could you tell me a little about [him/her]?" (to allow the bereaved to reflect on the life of the deceased loved one), and (2) "How have you been doing since [his/her] death?" (to show concern about the wellbeing of the bereaved since the loss). No aspect of the interviews was analyzed as a part of this study. This was followed by a second assessment session approximately six months later (T2). The total length of the sessions was approximately 1-3 hours at T1 and 2-4 hours at T2.

\subsection{Measures}

\subsubsection{Inventory of Complicated Grief-Revised (ICG-R; [23])}

The ICG-R assesses grief symptoms indicative of long-term dysfunction in bereavement. Using 34 items, rated on a 5-point Likert scale, the ICG-R evaluates severity of grief symptomatology on items such as I feel that I have trouble accepting the death or Ever since. died I feel like I have lost the ability to care about other people or I feel distant from people I care about. High internal consistency (Cronbach's $\alpha=0.95$ ) has been reported for the ICG-R in samples of both normative [54] and traumatic, premature loss [26]. Laurie and Neimeyer [55] found this measure to have high reliability ( $\alpha=0.95$ ) in their sample, which included African American homicidally bereft individuals. In the present sample, the ICG-R also showed had adequate internal consistency (T1, $\alpha=0.94$; T2 $\alpha=0.95$ ).

\subsubsection{Beck Depression Inventory II (BDI-II; [56])}

The BDI-II is a self-report measure, with 21 items assessing levels of depression on a 4-point scale, which includes items such as I have lost most of my interest in other people or things. Studies of traumatized adults showed high internal reliability for the BDI-II ( $\alpha=0.92$; [57]). Likewise, high internal consistency was found in the present sample (T1, $\alpha=0.92 ; \mathrm{T} 2, \alpha=0.95$ ).

\subsubsection{PTSD Checklist-Civilian Version (PCL-C; [58])}

The PCL-C is a 17-item measure that directly corresponds to the DSM-IV-TR (Diagnostic and Statistical Manual of Mental Disorder-text revision; American Psychiatric Association, 2000) criteria for PTSD. In this study, the instructions were modified to direct participants to answer questions with regard to their reaction to the homicide. Respondents rate levels of psychological impairment on a 1-5 scale in response to questions such as: Being "super-alert" or watchful or on guard? Items assess reexperiencing of the trauma, emotional numbing, avoidance of trauma-related reminders, and heightened arousal. The PCL-C has shown high reliability in previous samples of bereaved individuals [21], and, also in our study, at T1 $(\alpha=0.92)$ and T2 $(\alpha=0.96)$. 


\subsubsection{Brief RCOPE}

To measure religious coping, we used the 21-item Brief RCOPE [34], which was developed as an efficient measure of religious coping, using subscales to assess positive- and negative religious coping with items such as, Sought help from God in letting go of my anger and Wondered whether God had abandoned me. The Brief RCOPE showed adequate internal consistency for both PRC and NRC subscales ( $\alpha=0.80$ and 0.69 respectively) in three distinct samples [34]. Cronbach's alphas for both subscales in our sample were somewhat stronger at both T1 and T2, PRC: $\alpha=0.88$, and $\alpha=0.93$; NRC: $a=0.79$, and $a=0.82$, respectively.

\subsubsection{Background Variables}

This study examined routinely used background variables such as age, gender, education, annual income, relationship status (whether the participant was currently involved in a romantic relationship), and time since loss (TSL). Additionally, we examined pre-death frequency of contact with the deceased (or contact), which was assessed by asking How often were you in contact with this person before he or she died?, and using the following response options: 2-7 times per week, once per week, every other week, once per month, less than once per month.

\subsection{Data Analysis Plan}

We sought to examine the relation between psychological distress (in the form of CG, PTSD, and depression) and positive- and negative religious coping to establish if psychological distress more strongly predicted religious coping or vice versa in a sample of 46 African American homicide survivors. Additionally, we endeavored to explore whether the predictive power of CG exceeded that of PTSD and depression in forecasting subsequent NRC. To avoid reporting spurious results due to confounding, a multivariate approach was implemented. Due to lack of normality of distribution of scores on the Brief RCOPE in our sample, prior to running analyses we transformed the PRC variable using the reflect and square root transformation method, and transformed the NRC variable using the logarithm (with zero values) method, as suggested by Tabachnick and Fidell [59] and Howell [60]. Prior to conducting regression analyses, we ran Pearson's correlations to determine direction and strength of relations between the bereavement distress measures (ICG-R, PCL-C, \& BDI-II), the PRC and NRC subscales of the Brief RCOPE, and background variables (see Measures section). Next, to determine $\mathrm{T} 1$ predictors of $\mathrm{T} 2$ outcomes, a series of hierarchical regression analyses was conducted, using total scores from the ICG-R, PCL-C, \& BDI-II and the PRC and NRC subscales, in each case controlling for $\mathrm{T} 1$ outcome scores and correlated demographic variables. Our rationale for inclusion of control variables in Step 1 of each regression was based on commonly used standards for choosing covariate order in sequential regression analysis [28,59], pp. 18, 138). Specifically, inclusion of T1 outcome scores was imperative to our repeated-measures, within-subjects design; inclusion of Contact was based on prior research showing that pre-death levels of contact between bereaved individuals and their deceased loved one specifically predicted CG [28]; [61]; and, TSL was included because of the relatively great variation between participants in terms of post-loss duration. 


\section{Results}

Table 1 summarizes the descriptive statistics for the background variables, religious coping, and bereavement distress measures used in this study. With regard to bereavement outcome, these results show elevated levels of CG at T1 and T2 compared to young adults in Currier et al's [25] sample $(M=59.5 ; S D=24.7)$, a subset of whom were homicidally bereaved $(28 \%, n=100)$, and elevated levels of depression at $\mathrm{T} 1$ and $\mathrm{T} 2$, compared to individuals suffering from community violence in Ramchand, Marshall, Schell, and Jaycox's [62] sample $(M=9.40 ; S D=8.45)$. However, their PTSD scores were comparable to violently bereaved individuals $(M=37.3 ; S D=12.9)$ in Bonanno et al's [21] study. Self-reports of homicide survivors in our sample revealed substantially higher levels of both PRC and NRC than other samples of distressed or bereaved individuals (see [20]).

In terms of the relation between TSL, and NRC and CG, contrary to Anderson et al's [47] study with mothers who had lost a child to homicide or fatal accident (TSL in years, $M=4.5 ; S D=2.7$ ), showing that higher grief was associated with less post-loss duration, results of Pearson's correlations in our study showed that with the exception of CG at T1 $(r=-0.31, p<0.05)$, neither CG nor NRC had a statistically significant association with TSL.

Additionally, our results revealed that a worse bereavement outcome (with the exception of depression at T1) was associated with NRC at both T1 and T2, and that (with the exception of PTSD at T1) PRC was uncorrelated with bereavement distress at either time point (see Table 2). Background variables (see Measures section) that showed a statistically significant association with bereavement distress or religious coping are presented in Table 2, and were controlled for in our statistical analyses. To determine if PTSD at T1 predicted PRC at T2, a hierarchical regression analysis was conducted. First, T1 PRC scores, TSL, and contact were entered in Step 1, and T1 PCL-C scores were entered in Step 2. In relation to PRC at T2, the total variance explained by the model as a whole was $22 \%$, $F(4,41)=3.31 p=0.02$; yet, after controlling for PRC scores at T1, TSL, and contact, T1 PTSD explained only $3 \%$ of the variance in PRC scores at T2 (PCL T1 $\beta=-0.18, p=0.27$ ).

To determine if NRC at T1 predicted bereavement distress (CG, PTSD, or depression) at T2, a series of three hierarchical regression analyses was conducted. First, T1 PCL-C scores, TSL, and contact were entered in Step 1, and T1 NRC scores were entered in Step 2. In relation to PTSD at T2, the total variance explained by the model as a whole was $66 \%$ (total model: $F(4,41)=21.07$, $p=0.001$ ), yet, after controlling for PCL-C scores at T1, TSL, and contact, T1 NRC explained only $1 \%$ of the variance in PTSD scores at T2 (T1 NRC $\beta=-0.12, p=0.25$ ). Second, T1 BDI-II scores, TSL, and contact were entered in Step 1, and T1 NRC scores were entered in Step 2. In relation to depression at $\mathrm{T} 2$, the total variance explained by the model as a whole was $50 \%$, (total model: $F(4,41)=10.08, p=0.001)$, yet, after controlling for BDI-II scores at T1, TSL, and contact, T1 NRC explained less than $0.01 \%$ of the variance in depression scores at T2 (T1 NRC $\beta=0.02, p=0.86$ ). Third, T1 ICG-R scores, TSL, and contact were entered in Step 1, and T1 NRC scores were entered in Step 2. In relation to $\mathrm{CG}$ at $\mathrm{T} 2$, the total variance explained by the model as a whole was $63 \%,(F$ (4, $41)=17.61, p=0.001)$, yet, after controlling for ICG-R scores at T1, TSL, and contact, T1 NRC explained less than $0.01 \%$ of the variance in CG scores at T2 (T1 NRC $\beta=0.015, p=0.89$ ). Overall, once T1 PTSD, depression, and CG scores and related background variables were taken into account, religious coping was not statistically significant in predicting psychological distress at T2. 
Table 2. Intercorrelations of Bereavement Outcome, Religious Coping, and Background Variables for African American Adults Bereaved by Homicide $(n=46)$.

\begin{tabular}{|c|c|c|c|c|c|c|c|c|c|c|c|c|}
\hline Variables & 1 & 2 & 3 & 4 & 5 & 6 & 7 & 8 & 9 & 10 & 11 & 12 \\
\hline 1. Positive Religious Coping T1 & & $0.37 * *$ & 0.04 & -0.05 & 0.03 & -0.15 & 0.07 & 0.01 & -0.00 & -0.05 & -0.17 & 0.22 \\
\hline 2. Positive Religious Coping T2 & & - & -0.21 & -0.21 & -0.14 & -0.18 & $0.29 *$ & -0.23 & -0.21 & -0.20 & -0.03 & $0.34 *$ \\
\hline 3. Negative Religious Coping T1 & & & - & $0.49 * * *$ & $0.41 * *$ & $0.33^{*}$ & $0.39 * *$ & $0.42 * *$ & $0.49 * *$ & $0.37 * *$ & -0.13 & -0.21 \\
\hline 4. Negative Religious Coping T2 & & & & - & $0.48 * *$ & $0.49 * * *$ & $0.39 * *$ & $0.50 * * *$ & 0.22 & $0.50 * * *$ & -0.19 & -0.14 \\
\hline 5. Complicated Grief T1 & & & & & - & $0.79 * * *$ & $0.72 * * *$ & $0.63 * * *$ & $0.50 * * *$ & $0.54 * * *$ & $-0.31 *$ & -0.23 \\
\hline 6. Complicated Grief T2 & & & & & & - & $0.76^{* * *}$ & $0.78 * * *$ & $0.58 * * *$ & $0.78 * * *$ & -0.20 & -0.15 \\
\hline 7. PTSD T1 & & & & & & & - & $0.81 * * *$ & $0.75 * * *$ & $0.78 * * *$ & -0.09 & $-0.36 * *$ \\
\hline 8. PTSD T2 & & & & & & & & - & $0.63 * * *$ & $0.83 * * *$ & -0.15 & -0.28 \\
\hline 9. Depression T1 & & & & & & & & & - & $0.70 * * *$ & -0.13 & -0.21 \\
\hline 10. Depression T2 & & & & & & & & & & - & -0.13 & -0.23 \\
\hline 11. Time since loss & & & & & & & & & & & - & -0.26 \\
\hline 12. Frequency of contact & & & & & & & & & & & & - \\
\hline
\end{tabular}


To evaluate our specific hypothesis that $\mathrm{CG}$ at $\mathrm{T} 1$ would be predictive of $\mathrm{NRC}$ at $\mathrm{T} 2$ to a greater degree than other forms of bereavement distress (i.e., PTSD \& depression), three hierarchical regression analyses were conducted. For each analysis, T1 NRC scores and correlated background variables were entered in Step 1 (i.e., TSL and contact) and T1 bereavement outcome scores (ICG-R, PCL-C, or BDI-II) were entered in Step 2 (see Table 3). Our results showed that neither PTSD at T1 (total model $F(4,41)=4.33, p=0.005$; PCL-C T1 $\beta=0.23, p=0.14$; variance explained by total model $=25 \%$, variance explained by $\mathrm{T} 1 \mathrm{PTSD}=4 \%$ ) nor depression at $\mathrm{T} 1$ (total model $F(4,41)=3.60, p=0.01$; BDI-II T1 $\beta=-0.05, p=0.77$; variance explained by total model $=26 \%$, variance explained by T1 depression $=0.02 \%$ ) predicted NRC at T2. However, consistent with our hypothesis, our results demonstrated that only CG at T1 was statistically significant in predicting NRC at T2, accounting for $7 \%$ of the unique variance after TSL, contact, and NRC at T1 were taken into account (total model: $F(4,41)=5.04 p=0.002$; CG T1 $\beta=0.32, p=0.04$ ). (Note: not controlling for correlated demographic variables, i.e., contact and TSL, did not positively affect significance levels at the commonly accepted 0.05 level for any predictors in our analyses).

Table 3. Summary of Hierarchal Regression Analysis for Time 1 Bereavement Outcomes Predicting Time 2 Religious Coping in African American Adults Bereaved by Homicide $(n=46)$.

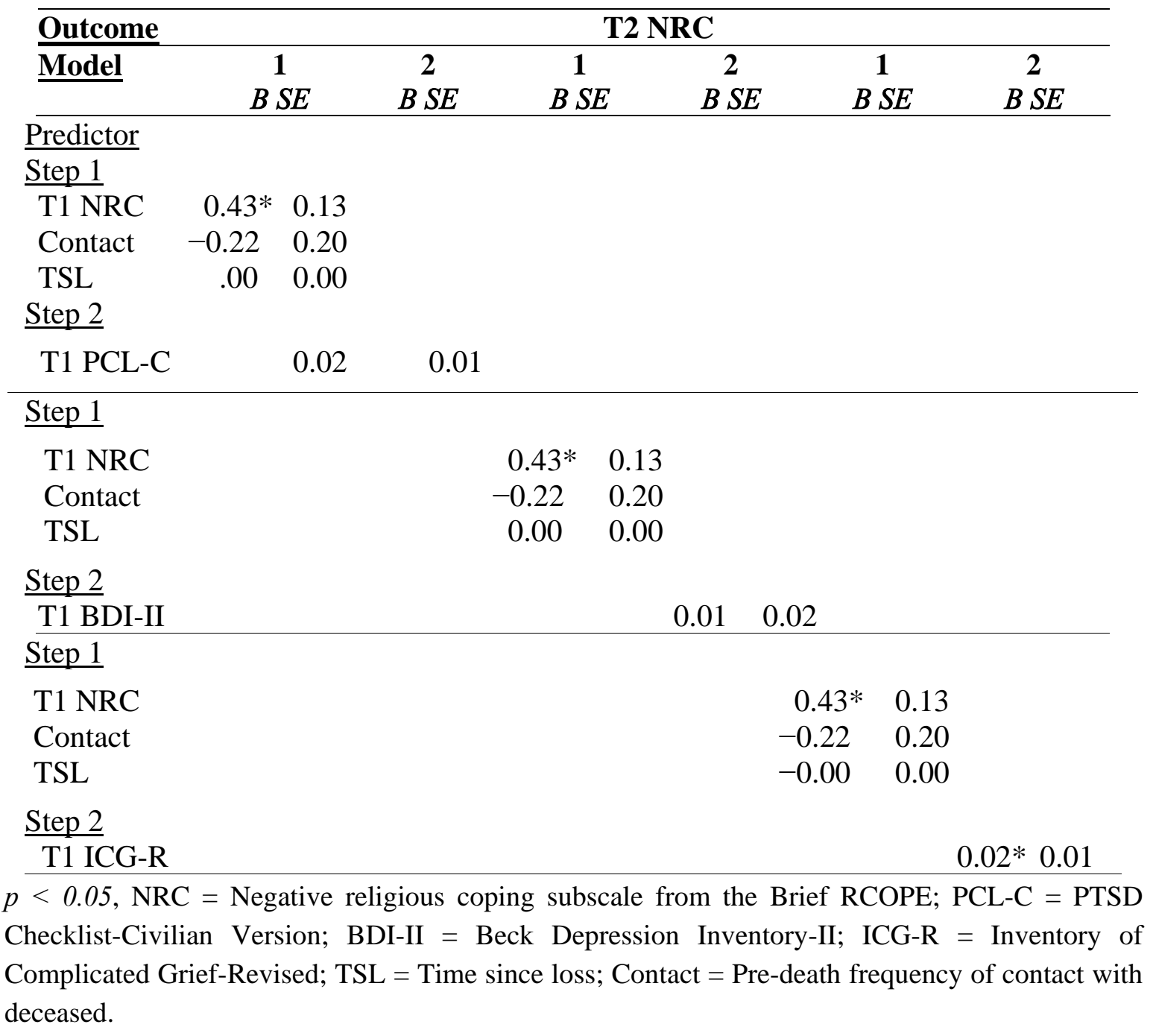




\section{Discussion}

In this study, we examined the relation between psychological distress (in the form of CG, PTSD, and depression) and positive- and negative religious coping to establish if psychological distress more strongly predicted religious coping or vice versa in a sample of 46 African American homicide survivors. African American individuals are particularly vulnerable to experiencing loss through homicide [9], a type of loss that has been shown to be more difficult than other types to bear [7] with serious consequences that often include the full range of symptomatology examined in this study. African Americans also are known for highly prizing their faith [13], and using it as resource when confronted with difficult trials [14,15]. Still, recent studies show that African Americans use both positive- and negative religious coping, sometimes at rates comparatively higher than their Caucasian counterparts [20], and, despite espousing high levels of spiritual engagement, are not exempt from experiencing spiritual crisis as a result of loss [20,51]. Although CG is a distinct and highly concerning form of bereavement outcome, we also recognized that PTSD and depression are worthy of attention in the context of homicide loss. Therefore, because the two forms of religious coping were differentially related to CG in our previous study with 46 African American homicide survivors [20], one goal of this research was to test to see if the same held true for PTSD and depression within the same sample.

Our results showing that individuals who had experienced a shorter bereavement at the time of assessment also struggled more in terms of their grief, were not surprising, given that homicide has been shown to be one of the most difficult types of loss to bear [7], and that the initial shock of it might be especially challenging. However, it also seems plausible that we should see more PRC and less NRC over time as that initial shock wears off. Instead, we saw no such association between religious coping and TSL. Consistent with our previous study, we found that the use of positive spiritual resources showed essentially no relation to bereavement distress at either time point. On the one hand, this calls into question the assumption that those respondents who rely more strongly on their religion will necessarily cope better with the extreme adversity of a loved one's murder, which could provide a severe test of even the most robust coping resource. On the other hand and more optimistically, the lack of relationship between positive spirituality and bereavement distress at either time point could be interpreted as supporting the relative immunity of constructive religious coping from erosion by the trauma of homicide: even in the face of such atrocity, religious mourners turn to their faith for succor and understanding.

Researchers who have monitored the bereavement trajectories of spiritually inclined grievers have reported that grief following the loss of a loved one can precipitate a spiritual crisis in some individuals [51]. We demonstrated the predictive nature of CG in an earlier study using this sample of violently bereaved adults by establishing that $\mathrm{CG}$ prospectively poses a risk for spiritual crisis in violently bereaved individuals [20]. Burke and her colleagues found that not only did CG predict NRC more generally but that it did so specifically at the item level, as well. Thus, having established CG as a risk factor for poor spiritual outcome following violent loss, in this study, we explored whether the predictive power of CG in terms of NRC would surpass that of PTSD and depression. Due to the multicollinearity between our distress measures (see Table 2), our finding that NRC was associated with nearly every form of bereavement distress at both time points also was not surprising. However, we had anticipated, and our analyses confirmed, that in terms of prospectively predicting NRC, CG 
remained the only significant predictor of spiritual crisis following loss in our sample. Perhaps this phenomenon can be explained by the nature of CG, itself - that the anguish over the loss of one's relationship to the deceased generalizes to a similar anguish in terms of one's relationship to God.

Our finding that CG supersedes PTSD and depression as a prospective predictor of CSG sharpens our understanding of both constructs, specifically in terms of treatment. Understanding the sourcethat spiritual distress in bereavement is directly related to the loss of the loved one, rather than to depressive or traumatic symptomatology per se-can aid professionals in assisting grievers as they search for meaning [63] and attempt to make spiritual sense of their loss [37,38,64]. For example, when prolonged and disabling grief clearly warrants intervention [65], evidence-based therapies that foster a healthy continuing bond with the deceased through imaginal conversations or other narrative techniques [66] could both ameliorate separation distress and lay the groundwork for similar reinforcement of an ethereal bond with the divine. Still, future research is needed to develop therapies specifically designed to address the plight of individuals who likely suffer from both CG and CSG. Such interventions may be especially relevant in the case of violently bereaved individuals, who could be especially susceptible to this often overlooked form of bereavement distress.

\subsection{Limitations to this Study}

Although this study brought increased clarity to the previous one by Burke and her colleagues [20], which was conducted with the same sample of violently bereaved African Americans, we recognize its obvious limitations. Despite our favorable rate of completers at our follow-up assessment, which afforded us a longitudinal design, we were restricted to some degree in terms of statistical analyses based on our fairly small sample size. Our sample also was predominantly female, and as such our findings of relatively high levels of CG might be a function of gender, as was the case in other studies, e.g. [26]. Thus, future studies of this nature should specifically solicit the participation of both males and females to provide a better interpretation of levels of grief symptomotology following the murder of a loved one. Additionally, with three or more assessment points or a pre-bereavement assessment, our understanding of the relation between bereavement distress and spiritual crisis likely would have been greater. For instance, given our data, we were unable to ascertain much about the spiritual wellbeing of our participants beyond our six-month follow-up assessment, when a shift from spiritual struggle to spiritual satisfaction or even growth might have been observed, as other cross-sectional studies have suggested [64].

Despite using widely recognized and well-validated measures of both religious coping and bereavement outcome, we nonetheless relied on self-report, which could have affected our ability to detect significant effects. Furthermore, our use of the Brief RCOPE [34] alone to measure a highly complex spiritual construct likely left important dimensions of spirituality unassessed, such as the constructive use of ritual for self-soothing, or negative coping processes such as praying for vengeance. Moreover, our use of highly correlated bereavement distress measures should also be noted as a limitation.

Although the distinctive nature of CG, PTSD, and depression has been established [16], a degree of symptom overlap remains across scales, which could have obscured unique features of each that might show different patterns of relation to spiritual coping or struggle. We also recognize that our findings 
bearing on the spiritual distress of African American homicidally bereaved individuals living in a large, mid-south city in the United States will not necessarily generalize to other individuals who are dissimilar in important respects from our sample.

Nevertheless, this study can serve as a springboard for future research linking spirituality or religious belief and practice to bereavement outcome. In addition to the obvious advocacy of sophisticated methodologies, and larger and more diverse samples, we join Stein and her colleagues [37] in encouraging investigation of a broader range of spiritual meaning making in grief, drawing on content coding of spiritual meanings derived from thematic analysis of mourners' qualitative responses [64] or theory-guided conceptualizations such as that of Büssing and Koenig [39], which views religious coping as a means of addressing spiritual needs for connection, purpose, meaning, and transcendence. We hope that our finding of a worrying link between negative religious coping on the part of spiritually inclined African Americans bereaved by homicide and their levels of depression, post-traumatic stress, and complicated grief, in combination with the uniquely predictive role of the latter in signaling later spiritual struggle, will encourage other researchers to join us in pursuing such questions.

\section{Acknowledgements}

This work was supported by the Tennessee Board of Regents for the project African Americans in Bereavement: Longitudinal Responses to Traumatic Loss. The authors gratefully acknowledge this support, as well as that of Victims to Victory, a non-governmental agency in Memphis, TN, serving those bereaved by homicide. Likewise, we acknowledge the invaluable help of Natalie L. Davis in this work.

\section{Reference}

1. Bonanno, G.A.; Kaltman, S. The varieties of grief experience. Clin. Psychol. Rev. 2001, 21, 705-734.

2. Bonanno, G.A.; Mancini, A.D. Bereavement-related depression and PTSD: Evaluating interventions In Psychological Interventions in Times of Crisis; Barbanel, L., Sternberg, R.J., Eds.; Springer: New York, NY, 2006; pp. 37-55.

3. Prigerson, H.G.; Frank, E.; Kasl, S.; Reynolds, C.; Anderson, B; Zubenko, G.S.; Houck, P.R.; George, C.J.; Kupfer, D.J. Complicated grief and bereavement related depression as distinct disorders: Preliminary empirical validation in elderly bereaved spouses. Am. J. Psychiatry 1995, 152, 22-30.

4. Shear, M.K.; Simon, N.; Wall, M.; Zisook, S.; Neimeyer, R.; Duan, N.; Reynolds, C.; Lebowitz, B.; Sung, S.; Ghesquiere, A.; Gorscak, B.; Clayton, P.; Ito, M.; Nakajima, S.; Konishi, T.; Melhem, N.; Meert, K.; Schiff, M.; O'Connor, M.; First, M.; Sareen, J.; Bolton, J.; Skritskaya, N.; Mancini, A.D.; Keshaviah, A. Complicated grief and related bereavement issues for DSM-5. Depress. Anxiety 2011, 28, 103-117.

5. Boelen, P.A.; Prigerson, H.G. The influence of symptoms of prolonged grief disorder, depression, and anxiety on quality of life bereaved adults: A prospective study. Eur. Arch. Psychiat. Clin. Neurosci. 2007, 257, 444-452. 
6. Neimeyer, R.A. Prolonged grief disorder. In Encyclopedia of Death and the Human Experience; Bryant, C., Peck, D., Eds.; Sage: Thousand Oaks, CA, USA, 2008.

7. Currier, J.M.; Holland, J.; Coleman, R.; Neimeyer, R.A. Bereavement following violent death: An assault on life and meaning. In Perspectives on Violence and Violent Death; Stevenson, R., Cox, G., Eds.; Baywood: Amityville, NY, USA, 2007.

8. Holland, J.; Neimeyer, R.A. An examination of stage theory of grief among individuals bereaved by natural and violent causes: A meaning-oriented contribution. Omega-J. Death Dying 2010, 61, 105-122.

9. Bureau of Justice Statistics. Homicide trends in the U.S: Trends by race. [Internet]. 2007. Available from http://www.ojp.usdoj.gov/bjs/homicide/race.htm (accessed on 23 December 2010)

10. Currier, J.M.; Holland, J.; Neimeyer, R.A. Sense making, grief and the experience of violent loss: Toward a mediational model. Death Stud. 2006, 30, 403-428.

11. Hays, J.C.; Hendrix, C.C. The role of religion in bereavement. In Handbook of Bereavement Research and Practice: Advances in Theory and Intervention; Stroebe, M.S., Hansson, R.O., Schut, H., Stroebe, W., Blink, E.V.D., Eds.; American Psychological Association: Washington, DC, USA, 2008; pp. 327-348.

12. Wortmann, J.H.; Park, C.L. Religion and spirituality in adjustment following bereavement: An integrative review. Death Stud. 2008, 32, 703-736.

13. Taylor, R.J.; Chatters, L.M.; Levin, J. Religion in Lives of African Americans: Social, Psychological, and Health Perspectives; Sage Publications: Thousand Oaks, CA, USA, 2004.

14. Barrett, R.K. Death and dying in the black experience: An interview with Ronald K. Barrett, Ph.D. Innov. End-of-Life Care 2001, 3, 1-9.

15. Barrett, R.K. Contemporary African-American funeral rites and traditions. In The Path Ahead: Readings in Death and Dying; DeSpelder, L., Strickland, A., Eds.; Mayfield: Mountain View, CA, USA, 1995; pp. 80-92.

16. Lichtenthal, W.G.; Cruess, D.G.; Prigerson, H.G. A case for establishing complicated grief as a distinct mental disorder in dsm-v. Clin. Psychol. Rev. 2004, 24, 637-662.

17. Prigerson, H.G.; Shear, M.K.; Jacobs, S.C.; Reynolds, C.F., III; Maciejewski, P.K.; Davidson, J.R.T.; Rosenheck, R.; Pilonis, P.A.; Wortman, C.B.; Williams, J.B.W.; Widiger, T.A.; Frank, E.; Kupfer, D.J.; Zisook, S. Consensus criteria for traumatic grief: A preliminary empirical test. Br. J. Psychiatry 1999, 174, 67-73.

18. Edmondson, D.; Park, C.L.; Chaudoir, S.R.; Wortmann, J.H. Death without God: Religious struggle, death concerns, and depression in the terminally ill. Psychol. Sci. 2008, 19, 754-758.

19. Hill, P.C.; Pargament, K.I. Advances in the conceptualization and measurement of religion and spirituality: Implications for physical and mental health research. Psychol. Relig. Spiritual. 2008, $1,2-17$.

20. Burke, L.A.; Neimeyer, R.A.; McDevitt-Murphy, M.E.; Ippolito, M.R.; Roberts, J.M. In the wake of homicide: Spiritual crisis and bereavement distress in an african american sample. Int. J. Psych. Relig. 2011, in press.

21. Bonanno, G.A.; Neria, Y.; Mancini, A.; Coifman, K.; Litz, B.; Insel, B. Is there more to complicated grief than depression and posttraumatic stress disorder? A test of incremental validity. J. Abnormal Psych. 2007, 116, 342-351. 
22. Prigerson, H.G.; Horowitz, M.J.; Jacobs, S.C.; Parkes, C.M.; Aslan, M.; Goodkin, K.; Raphael, B.; Marwit, S.J.; Wortman, C.; Neimeyer, R.A.; Bonanno, G.; Block, S.D.; Kissane, D.; Boelen, P.; Maercker, A.; Litz, B.; Johnson, J.G.; First, M.B.; Maciejewski, P.K. Prolonged grief disorder: Psychometric validation of criteria proposed for dsm-v and icd-11. PLoS Med. 2009, 6, 1-12.

23. Prigerson, H.G.; Jacobs, S.C. Traumatic grief as a distinct disorder: A rationale, consensus criteria, and a preliminary empirical test. In Handbook of Bereavement Research; Stroebe, M.S., Hansson, R.O., Stroebe, W., Schut, H., Eds.; American Psychological Association: Washington, DC, USA, 2001; pp. 613-645.

24. Holland, J.M.; Neimeyer, R.A.; Boelen, P.A.; Prigerson, H.G. The underlying structure of grief: A taxometric investigation of prolonged and normal reactions to loss. J. Psychopathol. Behav. Assess. 2009, 31, 190-201.

25. Goldsmith, B.; Morrison, R.S.; Vanderwerker, L.C.; Prigerson, H. Elevated rates of prolonged grief disorder in african americans. Death Stud. 2008, 32, 352-265.

26. Keesee, N.J.; Currier, J.M.; Neimeyer, R.A. Predictors of grief following the death of one's child: The contribution of finding meaning. J. Clini. Psychol. 2008, 64, 1145-1163.

27. Shear, M.K.; Jackson, C.T.; Essock, S.M.; Donahue, S.A.; Felton, C.J. Screening for complicated grief among project liberty service recipients 18 months after september 11, 2001. Psychiatr. Serv. 2006, 57, 1291-1297.

28. McDevitt-Murphy, M.E.; Neimeyer, R.A.; Burke, L.A.; Williams, J.L. Assessing the toll of traumatic loss: Psychological symptoms in African Americans bereaved by homicide. In preparation.

29. Gamino, L.A.; Sewell, K.W.; Easterling, L.W. Scott and caucasian grief study phase 2: Toward an adaptive model of grief. Death Stud. 2000, 633-660.

30. Lichtenthal, W.G.; Currier, J.M.; Neimeyer, R.A.; Keesee, N.J. Sense and significance: A mixed methods examination of meaning-making following the loss of one's child. J. Clin. Psychol. 2010, 791-812.

31. Kochanek, K.D.; Murphy, S.L.; Anderson, R.N.; Scott, C. Deaths: Final data for 2002. Natl. Vital Statist. Rep. 2004, 53, 1-16.

32. Bonanno, G.A. Loss, trauma and human resilience. Am. Psychol. 2004, 59, 20-28.

33. Carver, C.S.; Scheier, M.F.; Weintraub, J.K. Assessing coping strategies: A theoretically based approach. J. Personal. Soc. Psychol. 1989, 56, 267-283.

34. Pargament, K.; Smith, B.; Koenig, H.; Perez, L. Patterns of positive and negative religious coping with major life stressors. J. Sci. Stud. Relig. 1998, 37, 710-724.

35. Hills, J.; Paice, J.A.; Cameron, J.R.; Shott, S. Spirituality and distress in palliative care consultation. J. Palliat. Med. 2005, 8, 782-788.

36. Pargament, K.I.; Koenig, H.G.; Tarakeshwar, N.; Hahn, J. Religious struggle as a predictor of mortality among medically ill elderly patients: A 2-year longitudinal study. Arch. Intern. Med. 2001, 161, 1881-1885.

37. Stein, C.H.; Abraham, K.M.; Bonar, E.E.; McAuliffe, C.E.; Fogo, W.R.; Faigin, D.A. Making meaning from personal loss: Religious, benefit finding, and goal-oriented attributions. J. Loss Trauma 2009, 14, 83-100. 
38. Pargament, K.; Keonig, H.; Perez, L. The many methods of religious coping. J. Clin. Psychol. 2000, 56, 519-543.

39. Büssing, A.; Koenig, H.G. Spiritual needs of patients with chronic diseases. Religions 2010, 1, 18-27.

40. McIntosh, D.N.; Silver, R.C.; Wortman, C.B. Religion's role in adjustment to a negative life event. J. Personal. Soc. Psychol. 1993, 65, 812-821.

41. Reed, M.D. Sudden death and bereavement outcomes: The impact of resources on grief symptomatology and detachment. Suicide Life Threat Behav. 1993, 23, 204-220.

42. Sherkat, D.E.; Reed, M.D. The effects of religion and social support on self-esteem and depression among the suddenly bereaved. Soc. Indicat. Res. 1992, 26, 259-275.

43. Richardson, V.E.; Balaswamy, S. Coping with bereavement among elderly widowers. Omega-J. Death Dying 2001, 43, 129-144.

44. Burke, L.A.; Neimeyer, R.A.; McDevitt-Murphy, M.E. African american homicide bereavement: Aspects of social support that predict complicated grief, ptsd and depression. Omega-J. Death Dying 2010, 61, 1-24.

45. Meert, K.L.; Thurston, C.S.; Thomas, R. Parental coping and bereavement outcome after the death of a child in the pediatric intensive care unit. Ped. Crit. Care Med. 2001, 2, 324-328.

46. Tarakeshwar, N.; Hansen, N.; Kochman, A.; Sikkema, K.J. Gender, ethnicity and spiritual coping among bereaved hiv-positive individuals. Ment. Health Relig. Cult. 2005, 8, 109-125.

47. Anderson, M.J.; Marwit, S.J.; Vandenberg, B.; Chibnall, J.T. Psychological and religious coping strategies of mothers bereaved by the sudden death of a child. Death Stud. 2005, 29, 811-826.

48. Thompson, M.P.; Vardaman, P.J. The role of religion in coping with the loss of a family member to homicide. J. Sci. Stud. Relig. 1997, 36, 44-51.

49. Pargament, K.; Ensing, D.; Falgout, K.; Olsen, H. God help me: I. Religious coping efforts as predictors of the outcomes to significant negative life events. Am. J. Commun. Psychol. 1990, 18, 793-824.

50. Cummings, J.P.; Pargament, K.I. Medicine for the spirit: Religious coping in individuals with medical conditions. Religions 2010, 1, 28-53.

51. Shear, M.K.; Dennard, S.; Crawford, M.; Cruz, M.; Gorscak, B.; Oliver, L. Developing a twosession intervention for church-based bereavement support: A pilot project. In Proceedings of the 22nd International Society Traumatic Stress Studies, Hollywood, CA, USA, 5-7 November 2006.

52. Batten, M.; Oltjenbruns, K.A. Adolescent sibling bereavement as a catalyst for spiritual development: A model for understanding. Death Stud. 1999, 23, 529-546.

53. Exline, J.J.; Martin, A. Anger toward God: A new frontier in forgiveness research. In Handbook of Forgiveness; Worthington, E.L., Ed.; Routledge: New York, NY, USA, 2005; pp. 73-88.

54. Schnider, K.R.; Elhai, J.D.; Gray, M.J. Coping style use predicts posttraumatic stress and complicated grief symptom severity among college students reporting a traumatic loss. J. Couns. Psychol. 2007, 54, 344-350.

55. Laurie, A.; Neimeyer, R.A. African americans and bereavement: Grief as a function of ethnicity. Omega: J. Death Dying 2008, 57, 173-193.

56. Beck, A.T.; Steer, R.A.; Brown, G.K. Manual for the Beck Depression Inventory-ii; Psychological Corporation: San Antonio, TX, USA, 1996. 
57. Scarpa, A.; Hurley, J.D.; Shumate, H.W.; Haden, S.C. Lifetime prevalence and socioemotional effects of hearing about community violence. J. Interpers. Violenc 2006, 21, 5-23.

58. Weathers, F.; Litz, B.; Herman, D.; Huska, J.; Keane, T. The PTSD checklist (PCL): Reliability, validity, and diagnostic utility. In Proceedings of the 11th International Society Traumatic Stress Studies: 2006, Nov. 5-7, San Antonio, TX, USA, 2006.

59. Tabachnick, B.G.; Fidell, L.S. Using Multivariate Statistics, 5th ed.; Allyn and Bacon: Boston, MA, USA, 2007.

60. Howell, D.C. Statistical Methods for Psychology, 6th ed.; Thomson Wadsworth: Belmont, CA, USA, 2007.

61. Neimeyer, R.A.; Baldwin, S.A.; Gillies, J. Continuing bonds and reconstructing meaning: Mitigating complications in bereavement. Death Stud. 2006, 30, 715-738.

62. Ramchand, R.; Marshall, G.N.; Schell, T.L.; Jaycox, L.H. Posttraumatic distress and physical functioning: A longitudinal study of injured survivors of community violence. J. Consult. Clin. Psychol. 2008, 76, 668-676.

63. Coleman, R.A.; Neimeyer, R.A. Measuring meaning: Searching for and making sense of spousal loss in later life. Death Stud. 2010, 34, 804-834.

64. Lichtenthal, W.G.; Currier, J.M.; Neimeyer, R.A.; Keesee, N.J. Sense and significance: A mixed methods examination of meaning-making following the loss of one's child. J. Clin. Psychol. 2010, 66, 791-812.

65. Currier, J.M.; Neimeyer, R.A.; Berman, J.S. The effectiveness of psychotherapeutic interventions for the bereaved: A comprehensive quantitative review. Psych. Bull. 2008, 134, 648-661.

66. Shear, K.; Boelen, P.; Neimeyer, R.A. Treating complicated grief: Converging approaches. In Grief and Bereavement in Contemporary Society: Bridging Research and Practice; Neimeyer, R.A., Harris, D., Winokuer, H., Thornton, G., Eds.; Routledge: New York, NY, USA, 2011; pp. 139-162.

(C) 2011 by the authors; licensee MDPI, Basel, Switzerland. This article is an open access article distributed under the terms and conditions of the Creative Commons Attribution license (http://creativecommons.org/licenses/by/3.0/). 